\title{
Effect of Mannose Specific Lectins $A S A L$ and GNA on the Feeding Behavior of BPH (Nilaparvata lugens stal.)
}

\author{
Y. Bharathi ${ }^{1}$, V.D. Reddy ${ }^{2}$, K.V. Rao ${ }^{2}$ and I.C. Pasalu ${ }^{3 *}$ \\ ${ }^{1}$ Department of Seed Science and Technology, Seed Research and Technology Centre, \\ Professor Jayashankar Telangana State Agricultural University, Rajendranagar, \\ Hyderabad-500030, Telangana, India \\ ${ }^{2}$ Centre for Plant Molecular Biology, Osmania University, Hyderabad, 500 007, India \\ ${ }^{3}$ Indian Institute of Rice Research, Rajendranagar, Hyderabad, 500030, India
}

*Corresponding author

\section{A B S T R A C T}

Rice (Oryza sativa) productivity is adversely impacted by numerous biotic and abiotic factors. An approximate $52 \%$ of the global production of rice is lost annually owing to the damage caused by biotic factors, of which $\sim 21 \%$ is attributed to the attack of insect pests. We have developed transgenic pyramided rice lines, endowed with enhanced resistance to major sap sucking insects, through sexual crosses made between two stable transgenic rice

\section{Keywords}

Transgenic rice, ASAL, GNA, Feeding behavior, Honeydew

Article Info

Accepted:

10 August 2018

Available Online:

10 September 2018 lines containing Allium sativum (ASAL) and Galanthus nivalis (GNA) lectin genes. Presence and expression of asal and gna genes in pyramided lines were confirmed by PCR and western blot analyses. Segregation analysis of $F_{2}$ disclosed digenic (9:3:3:1) inheritance of the transgenes. Homozygous $\mathrm{F}_{3}$ progenies plants carrying asal and gna genes were identified employing genetic and molecular methods besides insect bioassays. Pyramided lines, infested with brown plant hopper (BPH), proved more effective in reducing insect survival, fecundity, feeding ability besides delayed development of insects as compared to the parental transgenics. Under infested conditions, pyramided lines were found superior to the both the parental transgenics in their seed yield potential. This study also reveals the feeding behavior of the BPH insects on both the pyramided as well as parental transgenic lines and the effect of mannose specific lectins asal and gna under the control of different promoters CaMV35S and Rss1 on the feeding behavior of BPH. BPH insects fed on GNA transgenic plants showed phloem specific feeding up to $72 \mathrm{~h}$ and later switched over to xylem feeding after $72 \mathrm{~h}$. In contrast, BPH insects fed on ASAL transgenic rice plants did not show any difference in the feeding behavior even after $96 \mathrm{~h}$. The pyramided lines appear promising and might serve as a novel genetic resource in rice breeding aimed at durable and broad based resistance against hoppers.

\section{Introduction}

Rice (Oryza sativa L.) is one of the world's most important crops, providing a staple food for nearly half of the global population (FAO,
2004). Almost $90 \%$ of the rice is grown and consumed in Asia (Khush and Brar, 2002). Approximately $15 \%$ of agricultural produce is lost every year to insects, and consequently farmers spend billions of US\$ yearly to 
provide effective control using chemical insecticides. Plants have been embattled in a war with the chewing, sucking and piercing insects for millions of years (Zhu-Salzman et al., 2005). The homopteran pests, rice brown plant hopper (Nilaparvata lugens), rice green leafhopper (Nephotettix virescens) and white backed planthopper (Sogatella furcifera) cause severe physiological damage to the rice plants, besides acting as vectors for major viral diseases (Mochida et al., 1979; Saxena and Khan, 1989; Dahal et al., 1997; Foissac et al., 2000). Chemical insecticides provide a simple way to control insect infestation, but use of agrochemicals without effective biosafety rules may lead to both environmental and health problems (Bajaj and Mohanty, 2005). In this context, genetic engineering of rice for insect resistance provides a potent, cost-effective and environment friendly option (Bajaj and Mohanty, 2005).

To develop new strategies for insect resistance crops, different insect-resistance genes, conferring resistance to major pests, have been identified from various sources for transferring them into cultivated crops (Estruch et al., 1997; Gatehouse and Gatehouse, 1998). In different crops, insect resistant transgenic plants were obtained through the introduction of Bacillus thuringiensis $(\mathrm{Bt})$ crystal protein (cry) genes, plant derived protease inhibitors (PIs) and lectins (Hilder et al., 1987; Boulter et al., 1990; Peferoen, 1992; Wunn et al., 1996; Nayak et al., 1997; Cheng et al., 1998; Datta et al., 1998; Maqbool et al., 2001, Nagadhara et al., 2003, 2004 and Yarasi et al., 2008, 2011).

Lectins are proteins or glycoproteins of nonimmune origin with one or more binding sites per subunit, which can reversibly bind to specific sugar segments through hydrogen bonds and Van Der Waals interactions (Lis and Sharon, 1998). Mannose-binding plant lectins have been proved to be promising candidates for the control of homopteran insect pests, not only for different insecticidal mechanisms, but also for their complementarities to $\mathrm{Bt}$ toxins and protease inhibitors. Earlier investigation indicated that the snowdrop lectin protein (GNA) isolated from the monocotyledonous plant, Galanthus nivalis (snowdrop), belonging to amaryllidaceous family, is toxic to sapsucking insects of rice when fed in artificial diet. Transgenic plants expressing GNA showed significant entomotoxic effects as evidenced by insect bioassays under controlled conditions (Hilder et al., 1995; Down et al., 1996; Gatehouse et al., 1996; Czapla, 1997; Rao et al., 1998; Foissac et al., 2000; Couty et al., 2001; Nagadhara et al., 2003, 2004). Similarly, bioassays based on artificial-diet-feeding system, using mannosespecific lectin from Allium sativum agglutinin (ASA and ASAL), showed antimetabolic effects towards BPH and GLH insects (Powell et al., 1995; Majumder et al., 2004). Transgenic rice expressing ASAL exhibited ample resistance against homopteran insects BPH and GLH (Saha et al., 2006) and for BPH, GLH and WBPH (Yarasi et al., 2008, 2011).

Earlier it was reported that, GNA under the control of Rice sucrose synthase promoter and a Maize ubiquitin promoter, confers resistance towards $\mathrm{BPH}$, despite the different levels of GNA as a proportion of total protein, plants derived from $\mathrm{pRSsGNA}$ and pUbiGNA gave similar results in the insect bioassays, suggesting that the phloem-specific promoter was also effective in delivering GNA to the insects (Rao et al., 1998). The expression efficiency of ASAL transgenics in rice was monitored, from two phloem specific promoters, RSs1, rolC and a constitutive CaMV35S promoter, rolC demonstrated to be stronger and more effective for engineering 
resistance to phloem limited viruses, than phloem-specific RSs1 promoter and CaMV35S (Saha et al., 2006).

The present study deals with the differential feeding behavior of $\mathrm{BPH}$ fed on transgenic rice plants expressing GNA under the control of phloem specific rice sucrose synthase promoter (Rss1) and transgenic rice plants expressing ASAL under the control of CaMV35S constitutive promoter. BPH insects fed on GNA trangenic plants showed phloem specific feeding up to $72 \mathrm{~h}$ and later switched over to xylem feeding after $72 \mathrm{~h}$. In contrast, $\mathrm{BPH}$ insects fed on ASAL transgenic rice plants did not show any difference in the feeding behaviour even after 96h. This report also demonstrates that the mannose specific lectins, GNA and ASAL conferred harmful effects towards these insects besides giving substantial protection to the rice plants.

\section{Materials and Methods}

\section{Transformation vectors}

Two Ti plasmid based super-binary vectors, containing the selectable marker gene bar driven by a CaMV 35S promoter; and the gna gene driven by the Phloem specific rice sucrose synthase promoter (RSs1) and asal gene driven by CaMV $35 \mathrm{~S}$ promoter were constructed. Expression cassettes of bar (CaMV 35S-bar-nos) (Rathore et al., 1993), gna (Rss1-gna-nos), and asal (CaMV 35Sasal-nos), were cloned at the multiple cloning site of the intermediate vector pSB11 (Komari and Kubo, 1999), obtained from Japan Tobacco Inc., Japan. The recombinant clones were introduced into Agrobacterium strain LBA4404 by triparental mating (Lichtenstein and Draper, 1985), and the resulting cointegrate vectors were designated as pSB111Rss1-gna-35Sbar and pSB111CaMV 35S-asal-35Sbar (Fig. 1a and b).
Genetic transformation studies using pSB111super-binary vectors

The local popular indica rice cultivar, namely, Chaitanya (susceptible to major insect pests) was used for genetic transformation experiments using the super-binary vectors pSB111Rss1-gna-35Sbar (Fig. 1a) and pSB111CaMV35S-asal-35Sbar (Fig. 1b). The GNA transgenic lines were developed and

\section{BASTA leaf dip assay}

Thirty to forty day old putative transformants were tested along with controls for their tolerance to the herbicide BASTA. The regenerated plants were tested by dipping the apical portion of leaf $(7-9 \mathrm{~cm})$ into $0.25 \%$ BASTA solution. The leaves were monitored after $72 \mathrm{~h}$ for signs of damage.

\section{Molecular analysis}

The transgenic plants employed in this study were well characterized by Southern and northern blot analysis (Nagadhara et al., 2003; Yarasi et al., 2008; Yarasi et al., 2011). The amount of GNA in the transgenic rice plants was estimated to be $0.1 \%-0.3 \%$ of total leaf soluble proteins, in comparison with GNA standards on the blots (Nagadhara et al., 2003; Yarasi et al., 2008; Yarasi et al., 2011). And the amount of ASAL in the transgenic rice plants was estimated to be $0.7 \%-1.49 \%$ of total leaf soluble proteins, in comparison with ASAL standards on the blots (Nagadhara et al., 2003; Yarasi et al., 2008; Yarasi et al., 2011).

\section{Insect bioassays}

In planta insect bioassays using $\mathrm{BPH}$ insects were carried out on homozygous transgenic rice lines and untransformed control plants. All insect bioassays were carried out at the Directorate of Rice Research (DRR) as 
described earlier (Nagadhara et al., 2003; Yarasi et al., 2008; Yarasi et al., 2011).

\section{Insect survival assays}

Thirty day old homozygous transgenic rice plants of ASAL transgenic line (T49) and GNA transgenic line (OU-1) and untransformed control plants were used to assess insect mortality /survival in no choice method. Early $1^{\text {st }}$ instar nymphs, 20 each, of BPH were independently released on each plant and confined in an insect proof nylan cage in 10 replications. Survival was monitored and observations were recorded on the nymphal survival for every 6 day intervals up to 24 days (Nagadhara et al., 2003; Yarasi et al., 2008; Yarasi et al., 2011). Data were analyzed using the sigma plot software, version 5.0, for windows (SPSS, Richmond, California, USA).

\section{Honeydew (liquid excreta) assay for} estimation of feeding ability of insects

The extent of insect feeding was measured by semi-quantitative assay of the honeydew produced (Nagadhara et al., 2003; Yarasi et al., 2008). Whatman No.1 filter paper dipped in a solution of bromocresol green $(2 \mathrm{mg} / \mathrm{ml}$ in ethanol) was used for honeydew estimation. The filter paper was placed at the base of each plant and covered with a plastic cup. On each plant five female adult insects of BPH, prestarved for $2 \mathrm{~h}$, were released separately, and allowed to feed for $24 \mathrm{~h}$ to $96 \mathrm{~h}$. Care was taken not to release gravid adult females. Insects excreta (honeydew) react with the bromocresol green on the filter paper leading to development of blue colored spots. The spots observed on the bromocresol green paper were blue or green in colour or seen as white or transparent spots. The blue colour spots indicate the feeding from phloem since $\mathrm{pH}$ is alkaline. The green colour indicates a transition from orange to blue colour formation. The white transparent spots indicate the feeding on the xylem since the water $\mathrm{pH}$ is neutral. The area of blue spots developed on the filter paper was measured using the millimeter graph paper and expressed in $1 \mathrm{~mm}^{2}$ units (Nagadhara et al., 2003; Yarasi et al., 2008; Yarasi et al., 2011). The observations were recorded for every $24 \mathrm{~h}$ by replacing the new filter paper.

\section{Results and Discussion}

Rice is being an important food crop is attacked by more than 100 insect species which cause significant economic loss in various regions. Pest problem increased with the intensification of irrigated rice production, which increases cost of production. Plant hoppers are common rice insect pests in Asian rice production regions. Hopper burn is a noncontagious disease of plants caused by the direct feeding damage of certain leafhoppers and plant hoppers. Hopper burn is caused by a dynamic interaction between complex insect feeding stimuli (termed hopper burn initiation) and complex plant responses (termed the hopper burn cascade). It has been emerged as a potential threat to rice production in tropical Asia. In the current "Post - Green Revolution era," emphasis is given on sustainability and efficiency rather than on further intensification with expensive inputs. In pest management, the challenge is to make natural non-chemical methods collectively more effective. Moreover botanical insecticides are naturally occurring chemicals extracted from plants.

The transgenic rice lines, containing asal and gna genes, were obtained by genetic transformation using Agrobacterium superbinary vectors pSB111Rss1-gna-35Sbar and pSB111CaMV35S-asal-35Sbar. Both the transgenic lines were thoroughly characterized by molecular, genetic and insect bioassays experiments. The presence and 
expression of transgenes (asal \& gna) in transgenic rice lines were confirmed through PCR, Southern, Northern, western blot analyses and insect bioassays (Fig. 2) (Yarasi et al., 2008, 2011). Although the constitutive CaMV35S gene promoter, used in many constructs for expression in transgenic plants, is expressed efficiently in phloem tissue, it was felt desirable to identify promoters that would show phloem-specific expression for use in producing rice with $\mathrm{BPH}$ resistance. Use of such promoters could give higher levels of expression in the phloem and would minimize exposure of non-target insects and other consumers of the plant material. Plant lectins are considered a complex and heterogeneous group of proteins due to the obvious differences in molecular structure, biochemical properties and carbohydratebinding specificity.

\section{Effect of GNA and ASAL on the survival of BPH}

BPH nymphs fed on homozygous ASAL and GNA transgenic rice plants showed a significant decline in survival from the $9^{\text {th }}$ day onwards (Fig. 3). BPH survival on ASAL transgenic rice plants reduced to a mean of $3.30 \pm 1.08$ insects /plant and on GNA transgenic rice lines $5.30 \pm 0.89$ insects/plant compared to a mean of $14.20 \pm 1.47$ insects/plant on control plants over a 24-day bioassay period (Fig. 3). The BPH nymphal survival on ASAL and GNA transgenic rice lines was reduced by $78.9 \%$ and $62.7 \%$ respectively, when compared to control plants.

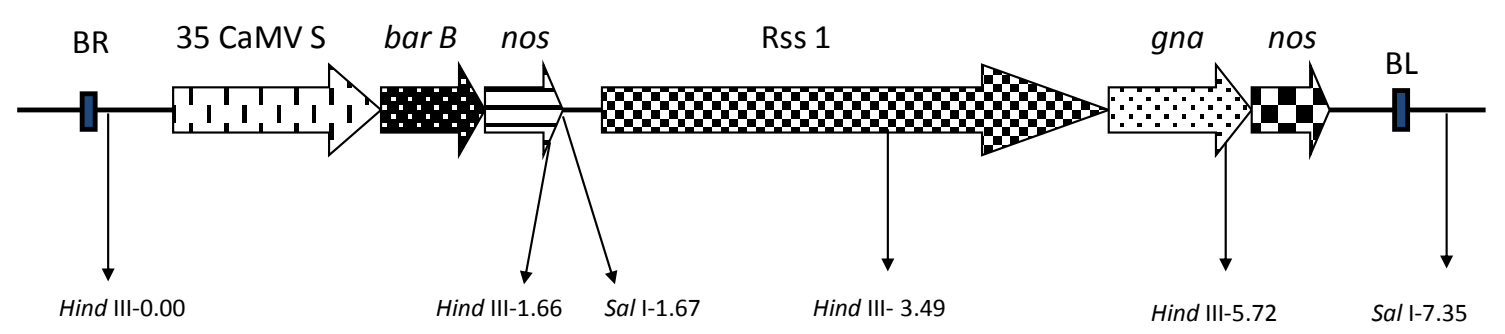

Fig.1a

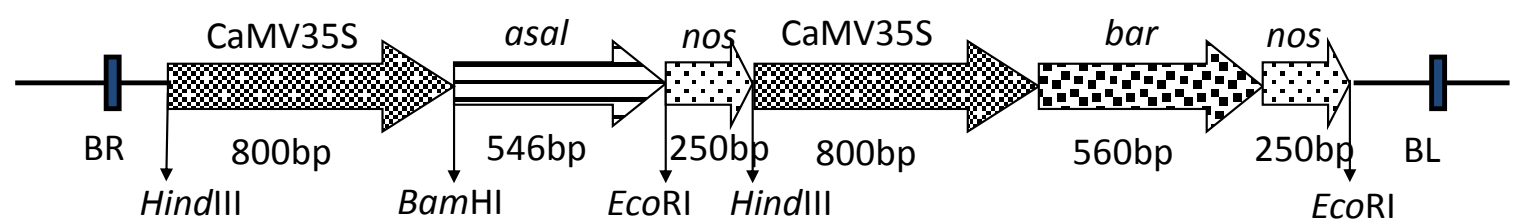

Fig.1b 

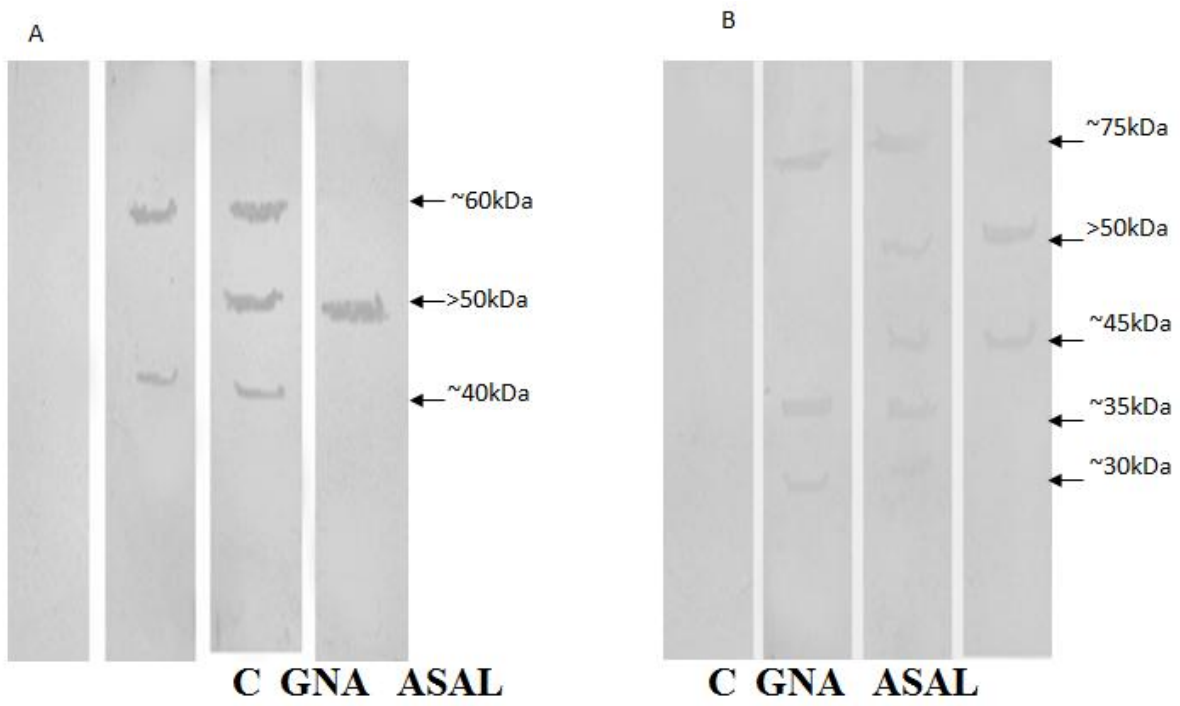

Fig.2 Western blot analysis from insect feeding on showing the ASAL and GNA transgenics

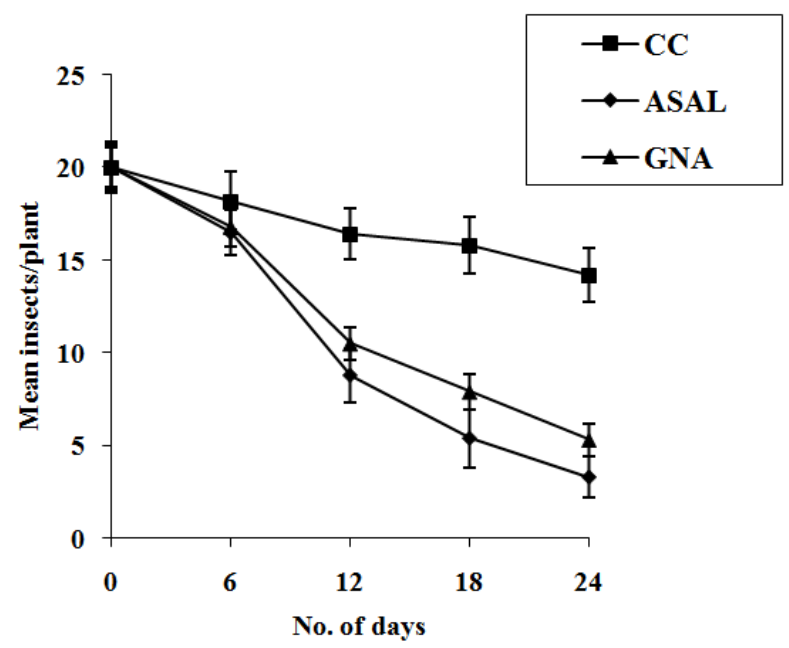

Fig.3 Mean Number of insects survived after feeding on the transgenic plants

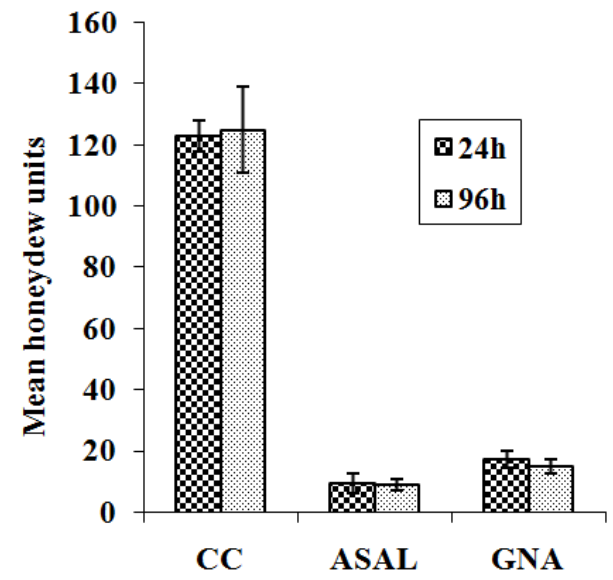

Fig.4 Mean Number of honeydew units after feeding on the transgenic plants 
Feeding after $24 \mathrm{~h}$

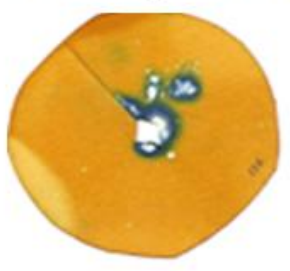

Control

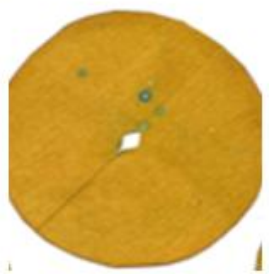

GNA

Feeding after $96 \mathrm{~h}$

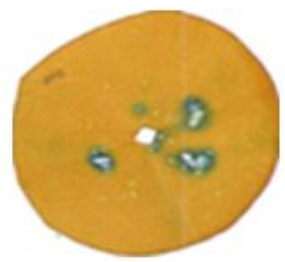

Control

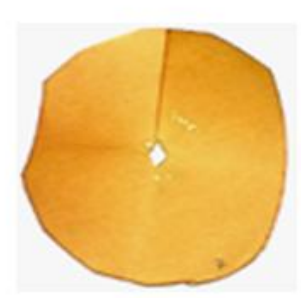

GNA

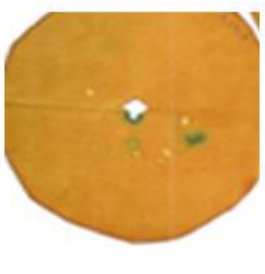

ASAL

Fig.5 Honeydew assay for BPH after feeding on the transgenic plants

Impact of transgenic rice lines (ASAL and GNA) on the feeding behaviour of BPH insects

Effect of ASAL and GNA on the feeding behaviour of $\mathrm{BPH}$ insects was assayed separately by estimating the amount of excreta (honeydew). A mean number of $7.30 \pm$ 1.10 and $16.10 \pm 1.30$ honeydew units (blue spots) were excreted by BPH insects fed on ASAL and GNA transgenic rice plants respectively, compared to a mean number of $94 \pm 3.50$ honeydew units on control plants after 24h of feeding (Fig.4). A mean number of $2.30 \pm 0.82$ and $1.10 \pm 0.53$ honeydew units (white spots) were excreted by BPH insects fed on ASAL and GNA transgenic rice plants respectively, compared to a mean number of $29 \pm 2.30$ honeydew units (i.e. white spots indicating the xylem feeding) were excreted on control plants (Fig.4) after $24 \mathrm{~h}$ of feeding.

A mean number of $6.80 \pm 1.29$ and $3.20 \pm 1.28$ honeydew units (blue spots) were excreted by $\mathrm{BPH}$ insects fed on ASAL and GNA transgenic rice plants respectively, compared to a mean number of $93 \pm 12.13$ honeydew units (i.e. blue spots indicating the phloem feeding) were excreted on control plants (Fig. 4) after $96 \mathrm{~h}$ of feeding. A mean number of $2.10 \pm 0.78$ and $12 \pm 4.23$ honeydew units (white spots) were excreted by BPH insects fed on ASAL and GNA transgenic rice plants respectively, compared to a mean number of $32 \pm 2.60$ honeydew units (i.e. white spots indicating the xylem feeding) were excreted on control plants (Fig. 4) after 96h of feeding.

After $24 \mathrm{~h}$ of feeding on control, ASAL and GNA transgenic rice plants by BPH insects the blue and white colored spots observed on the bromocresol green papers were measured. The blue spots indicate the phloem feeding of the insects and white spots indicate the xylem feeding of the insects. A mean of $9.60 \pm 2.30$ and $17.20 \pm 2.70$ honeydew units (blue spots) were excreted by BPH insects fed on ASAL and GNA transgenic plants respectively, compared to a mean of $123 \pm 5.10$ honeydew units on control plants (Fig. 5) after 24h of 
feeding, showing a significant reduction of $92.1 \%$ and $86.1 \%$ in the feeding of $\mathrm{BPH}$ insects respectively, on ASAL and GNA transgenic rice plants, compared to control plants. The mean of $8.90 \pm 1.90$ and 15.20 \pm 2.30 honeydew units (blue spots) were excreted by BPH insects fed on ASAL and GNA transgenic rice plants respectively, compared to a mean of $125 \pm 14.00$ honeydew units on control plants (Fig. 5) after 96h of feeding, exhibiting a significant reduction of $92.8 \%$ and $87.8 \%$ in the feeding behaviour of BPH insects, on ASAL and GNA transgenic rice plants compared to control plants.

The rice brown planthopper (BPH; Nilaparvata lugens) is a serious pest of rice crops throughout Asia, damaging plants both through its feeding behavior and by acting as a virus vector. Like many homopteran pests of crops, it is primarily a phloem feeder, abstracting sap via specially adapted mouthparts. An artificial diet bioassay system for this pest was developed to allow the effects of potentially insecticidal proteins to be assayed. Several lectins and oxidative enzymes were found to be toxic to $\mathrm{BPH}$. $\mathrm{BPH}$ in addition to causing direct damage to the plant itself, also act as the vector for stunt viruses. Special attention was focused on homopteran rice pests such as $\mathrm{BPH}$ because regular insecticide spraying under intensive farming practices to control these insects has resulted in the loss of natural predators and the selection of pesticide-resistant biotypes allowing pest resurgence. Although $\mathrm{BPH}-$ resistant varieties were identified from the germplasm collection, resistance-breaking biotypes have rapidly overcome resistance mechanisms introduced by conventional breeding. As a component of IPM strategies for rice, new resistant varieties are required. Homoptera are sap-sucking insects or phloem-feeders, and so it was considered that in addition to expressing the protein constitutively, specific expression in the phloem would deliver the protein efficiently to the insect while minimizing any potential undesirable accumulation of the protein in other parts of the plant. More importantly, the transgenes in most of the plants were inherited as Mendelian traits.

\section{References}

Aldemita, R.R., Hodges, T.K., 1996. Agrobacterium tumefaciens mediated transformation of indica and japonica rice varieties. Planta 199, 612-617.

Bajaj, S., Mohanty, A., 2005. Recent advances in rice biotechnology-towards genetically superior transgenic rice. Plant Biotechnology Journal 3, 275-307.

Boulter, D., Edwards, G.A., Gatehouse, A.M.R., Gatehouse, J.A., Hilder, V.A., 1990. Additive protective effects of different plant derived insect resistance genes in transgenic tobacco plants. Crop Protection 9, 351-354.

Cheng, X.Y., Sardana, R., Kaplan, H., Altosoar, I., 1998. Agrobacterium transformed rice expressing synthetic crylA (b) and crylA (c) genes are highly toxic to striped stemborer and yellow stemborer. Proceedings of National Academy of Science USA 95, 2767-2772.

Couty, A., Down, R.E., Gatehouse, A.M.R., Kaiser, L., Pham-Delegue, M.H., Poppy, G.M., 2001. Effects of artificial diet containing GNA and GNA expressing potatoes on the development of the aphid parasitoid Aphidius ervi haliday (Hymenoptera: Aphididae). Journal of Insect Physiology 47, 13571366.

Czapla TH., 1997. Plant lectins as insect control proteins in transgenic plants. In Advances in Insect Control: the role of transgenic plants Edited by: Carozzi N, Koziel M. Taylor \& Francis Ltd London UK, 123-138. 
Dahal, G., Hibino, H., Aguiero, V. M., 1997. Population characteristics and tungro transmission by Nephotettix virescens (Hemiptera: Cicadellidea) on selected resistant rice cultivars. Bulletin of Entomology Research 87, 387-395.

Datta, K., Vasquez, A., Tu, J., Torrizo, L., Alam, M.F., Oliva, N., Abrigo, E., Khush, G.S., Datta, S.K., 1998. Constitutive and tissue-specific differential expression of crylA (b) gene in transgenic rice plants conferring enhanced resistance to rice insect pest. Theoretical and Applied Genetics 97, 20-30.

Down, R.E., Gatehouse, A.M.R., Hamilton, W.D.O., Gatehouse, J.A., 1996. Snowdrop lectin inhibits development and decreases fecundity of the glasshouse potato aphid (Aulacorthum solani) when administered in vitro and via transgenic plants both in laboratory and glasshouse trials. Journal of Insect Physiology 42, 1035-1045.

Estruch, J.J., Carozzi, N.B., Desai, N., Duck, N.B., Warren, G.W., Koziel, M.G., 1997. Transgenic plants: An emerging approach to pest control. Nature Biotechnology 15, 137-141.

FAO. Website 2004. International year of rice.

http.//www.fao.org/rice2004/en/aboutric e.htm. (Accessed June 28, 2007).

Foissac, X., Loc, N.T., Christou, P., Gatehouse, A.M.R., Gatehouse, J.A., 2000. Resistance to green leafhopper (Nephotettix virescens) and brown planthopper (Nilaparvata lugens) in transgenic rice expressing snowdrop lectin (Galanthus nivalis agglutinin; GNA). Journal of Insect Physiology 46, 573-583.

Gatehouse, A.M.R., Down, R.E., Powell, K.S., Sauvion, N., Rahbe, Y., Newell, C.A., Merryweather, A., Hamilton, W.D.O., Gatehouse, J.A., 1996.
Transgenic potato plants with enhanced resistance to peach-potato aphid Myzus persicae. Entomologia et Experimentalis Applicata 79, 295-307.

Gatehouse, A.M.R., Gatehouse, J.A., 1998. Identifying proteins with insecticidal activity: use of encoding genes to produce insect-resistant transgenic crops. Pesticide Science 52, 165-175.

Hilder, V.A., Gatehouse, A.M.R., Shreeman, S.E., Barker, R.F., Boulter, D., 1987. A novel mechanism of insect resistance engineered into tobacco. Nature 330, 160-163.

Hilder, V.A., Powell, K.S., Gatehouse, A.M.R., Gatehouse, J.A., Gatehouse, L.N., Shi, Y., Hamilton, W.D.O., Merryweather, A., Newell, C.A., Timans, J.C., Peumans, W.J., Vandamme, E.J.M., Boulter, D., 1995. Expression of snowdrop lectin in transgenic tobacco plants results in added protection against aphids. Transgenic Research 4, 18-25.

Khush, G.S., Brar, D.S., 2002. Biotechnology for rice breeding: progress and potential impact. Proceedings of the $20^{\text {th }}$ Session. International Rice Commission. Bangkok, 23-26.

Komari, T., Kubo, T., 1999. Methods of genetic transformation: Agrobacterium tumefaciens. In: Vasil, I.K. (Ed.), Molecular Improvement of Cereal Crops. Kluwer Academic Publishers pp, 43-82.

Lichtenstein, C., Draper, J., 1985. Genetic engineering of plants. In DNA cloning a practical approach edited by: Glover D.M. Washington, DC. IRL Press, 67118.

Lis, H., Sharon, N., 1998. Lectins: carbohydrate-specific proteins that mediate cellular recognition. Chemical Review 98, 637-674.

Majumder, P., Banerjee, S., Das, S., 2004. Identification of receptors responsible 
for binding of the mannose specific lectin to the gut epithelial membrane of the target insects. Glycoconjugate Journal 20, 525-530.

Maqbool, S.B., Riazuddin, S., Loc, N.T., Gatehouse, A.M.R., Gatehouse, J.A., Christou, P., 2001. Expression of multiple insecticidal genes confers broad resistance against a range of different rice pests. Molecular Breeding 7, 85-93.

Mochida, O., Wahyu, A., Surjani, T.K. 1979. Some consideration on Screening Resistant Cultivars/Lines of Rice Plant to the Brown Planthopper, Nilaparvata lugens (Stal) (Homoptera, Delphacidae). IRRI, Los Banos, Phillippines Pp, 1-9.

Nagadhara, D., Ramesh, S., Pasalu, I.C., Rao, Y.K., Krishnaiah, N.V., Sarma, N.P., Bown, D.P., Gatehouse, J.A., Reddy, V.D., Rao, K.V., 2003. Transgenic indica rice resistant to sap sucking insects. Plant Biotechnology Journal 1, 231-240.

Nagadhara, D., Ramesh, S., Pasalu, I.C., Rao, Y.K., Sarma, N.P., Reddy, V.D., Rao, K.V., 2004. Transgenic rice plants expressing the snowdrop lectin gene (gna) exhibit high-level resistance to the whitebacked planthopper (Sogatella furcifera). Theoretical and Applied Genetics 109, 1399-1405.

Nayak, P., Basu, D., Das, S., Basu, A., Ghosh, M., Sen, S.K., 1997. Transgenic elite indica rice plants expressing Cry1 AC $\delta$ endotoxin of Bacillus thuringiensis are resistant against yellow stem borer (Scirpophaga incertulas). Proceedings of National Academy Science USA. 94, 2111-2116.

Peferoen, M., 1992. Engineering of insectresistant plants with Bacillus thuringiensis crystal protein genes. In: Plant Genetic Manipulation for Crops Protection (Gatehouse, A.M.R., Hilder,
V.A. and Boulter, D., eds), Wallingford, UK: CAB International pp, 135-153.

Powell KS, Gatehouse AMR, Hilder VA, Gatehouse IA (1993). Anti-metabolic effects of plant lectins and plant and fungal enzymes on the nymphal stages of 2 important rice pests, Nilaparvata lugens and Nephotettix virescens. Entomol Exp Appl. 66: 119-126.

Powell, K.S., Gatehouse, A.M.R., Hilder, V.A., Gatehouse, J.A., 1995a. Antifeedant effects of plant lectins and an enzyme on the adult stage of rice brown planthopper, Nilaparvata lugens. Entomologia et Experimentalis Applicata 75, 51-59.

Rao, K.V., Rathore, K.S., Hodges, T.K., Fu, X., Stoger, E., Sudhakar, D., Williams S., Christou P., Bharathi M., Bown, D.P., Powell, K.S., Spence, J., Gatehouse, A.M.R., Gatehouse, J.A., 1998. Expression of snowdrop lectin (GNA) in transgenic rice plants confers resistance to rice brown planthopper. Plant Journal 15, 469-477.

Saha, P., Majumder, P., Dutta, I., Ray, T., Roy, S.C., Das, S., 2006. Transgenic rice expressing Allium sativum leaf lectin with enhanced resistance against sap-sucking insect pests. Planta 223, 1329-1343.

Sambrook, J., Russell, D.W., 2001. In: Molecular Cloning: A Laboratory Manual. (Argentine J. ed.) Vol. 1, 2, 3. Cold Spring Harbor Laboratory Press, NY.

Saxena, R.C., Khan, Z.R., 1989. Factors effecting resistance to rice varieties to planthopper and leafhopper pests. Agricultural Zoological Review 3, 97132.

Wunn, J., Kloti, A., Burkhardt, P.K., Chosh Biswas, G.C., Launis, K., Iglesias, V.A., Potrykus, I., 1996. Transgenic indica rice breeding line IR-58 expressing a synthetic crylA (b) gene from Bacillus 
thuringiensis provides effective insect pest control. Bio/Technology 14, 171176.

Yarasi, B., Vijaya, K.S., Pasalu, I.C., Reddy, V.D., Rao, K.V., 2008. Transgenic rice expressing Allium sativum leaf agglutinin (ASAL) exhibits high-level resistance against major sap sucking pests. BMC Plant Biology 8, 102.

Yarasi, B., Vijaya, K.S., Pasalu, I.C., Reddy, V.D., Rao, K.V., 2011. Pyramided rice lines harbouring Allium sativum (asal) and Galanthus nivalis (gna) lectin genes impart enhanced resistance against major sap-sucking pests. Journal of Biotechnology (152), 63-71.

Zhu-Salzmann, K., Shade, R.E., Koiwa, H., Salzman, R.A., Narasimhan, M., Bressam R.A., Hasegawa, P.M., Murdock, L.L., 1996. Carbohydrate binding and resistance to proteolysis control insecticidal activity of Griffonia simplicifolia lectin II. Proceedings of National Academy of Sciences USA 95, $15123-15128$.

\section{How to cite this article:}

Bharathi, Y., V.D. Reddy, K.V. Rao and Pasalu, I.C. 2018. Effect of Mannose Specific Lectins $A S A L$ and GNA on the Feeding Behavior of BPH (Nilaparvata lugens stal.). Int.J.Curr.Microbiol.App.Sci. 7(09): 1426-1436. doi: https://doi.org/10.20546/ijcmas.2018.709.171 